\title{
The Exploration and Practice of Promoting the Application-oriented Talents Quality by "Six-Cooperation" to "Six-Fields" Integration
}

\author{
Shuang LIANG \\ Shenyang Technology College, Fushun, LiaoNing China, 113122 \\ email: Is_happiness@163.com
}

LIANG Shuang*

Keywords: Application Type; Conversion Type; Co-op; Innovation and Entrepreneurship; Teaching Reform

\begin{abstract}
As a local College, Shenyang Technology College aims at cultivating high-quality applied talents who are skilled in the fields of production, construction, management, and service and "know profession, strong skills, good at cooperation, expert in work" that meet market demands. Industry-profession and college-enterprise cooperation is the main line,"six-cooperation" is the method, closely surrounding the market demand. Professional group matching industry chain, student learning content matching professional standards, teaching process matching production process. Student can high-quality get a job and some of can start their own business, achieve "profession-industry" " study - career" "employment-pioneer" high integration, which can make outstanding contributions for local economic development.
\end{abstract}

\section{Introduction}

Shenyang Technology college thoroughly implemented "On Guiding Some Local Undergraduate Colleges to Transition to Applied Types”, and fully implemented the "Liaoning Provincial People's Government's Implementation Opinions on Promoting the Transition from Undergraduate Universities to Application-types” ([2015] 89) , further promoted in the transformation and development of applied colleges, and firmly established college direction with applied technology. Demand-oriented, student-centered, value-creating as the goal, deepening reform, strengthening connotation construction, cultivating the practical ability and innovative spirit of applied talent adapted to the needs of Liaoning's regional economy, social development, industrial upgrading, and public service development.

\section{Necessity of Transformation and Development of Local Universities}

\section{Inherent Requirement to Adapt to the Structural Adjustment of Higher Education}

In recent years, the contradiction between the talents supply in universities and the market needs has become increasingly prominent. On the one hand, it is difficult for college graduates to find employment; on the other hand, the supply of high-level applied talents is insufficient. As the country changes its economic growth mode and industrial transformation and upgrading, it must optimize the structure of higher education and realize the strategic adjustment of the talent cultivation structure, while the important task of training applied talents lies in local universities. Therefore, Shenyang Technology college has actively responded to the transformation requirements and increased the quality of applied talents ${ }^{[1]}$. 


\section{Objective Requirement to Better Serve the Economic and Social Development of Liaoshen Area}

Serving local economic and social development is an important responsibility and the only way for the survival and development of the college. The rejuvenation of Liaoning's old industrial base requires strong personnel support. Only by actively implementing the transformation and development strategy can the college better bear this historical mission and serve the economic and social development of Liaoshen area.

\section{Realistic Choice for the Sustainable Development of the College itself}

Shenyang Technology College, as a new local undergraduate college, must take the initiative to adapt to regional economic development, pay attention to the connotation construction, and win the college's own development space, create conditions and win opportunities for the college's characteristics development.

Through transformation development, promote scientific positioning of the professional group of our university, develop professional groups in an all-round way. It has actively carried out teaching reforms, implemented different reform modes, mobilized students' enthusiasm for learning, and vigorously improved students' practical ability.

\section{The Path of Local Universities Transformation Development}

Transformation development need to go through a continuous and complex process involving many global issues closely related to the college's science development. However, the author believes that if this task is combined with "professional-industry," "study-professional," and "employment-startup", which will help the college to further promote the transformation development and continuously improve the personnel training quality.

\section{Market Demand is the Education Direction, and Scientific Positioning Promotes Transformation.}

Local universities have firmly grasped the "application type" and "locality" in the process of transformation development. According to the local market demand, they who are "knowing professional, strong skills, work together, and good at work" high-quality application-oriented talents are trained to meet the market need of production, construction, management, and service. Co-op as the main line, “6-co-op”as the means [2, 3], closely surrounding the market demand, professional group docking industry chain, student education Contents match occupational standards, teaching process is connected to the process of teaching reforms, it can help student to high-quality employment and meet the need of some students in their own business. Which can achieve the height integration in "professional-industry" "study-career" "employment-entrepreneurship", improve the quality of applied talents, and make outstanding contributions to local economic development. 


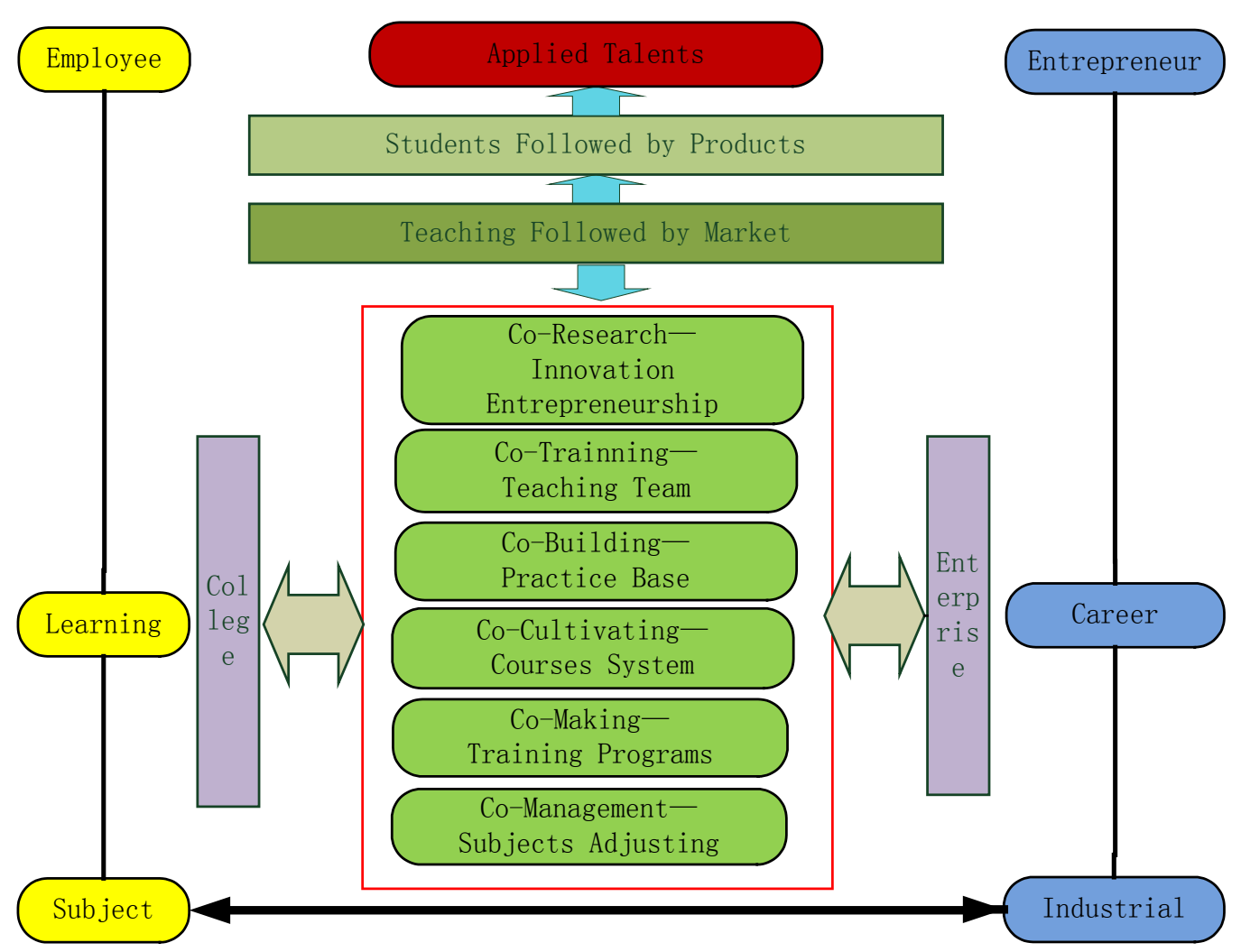

Fig.1 Applied Talents in “6-co-op”modes to “6-fields”Coopration

\section{Professional Group Docking Industry Chain, Professional Adjusting with Market.}

In order to adapt to the needs of economic transformation and upgrading and industrial restructuring development, adhering to integration of industries and professions ${ }^{[4]}$, the college has established a professional construction committee who are composed of industry experts and college experts. According to the idea of the professional groups docking industry chain ,aim at the industrial groups such as equipment manufacturing, transportation, modern service, and deep processing of agricultural products in the Liaoning-Shenyang region, and focuses on building such applied specialty groups as the specialized mechanical group, transportation group, financial group, management group, communication media group, plant production group, etc.. 6 relevant majors such as costume without industry support in the region were withdrawn. and welding technique majors which the first voluntary acceptance rate was low was suspended. 5 relevant majors such as agricultural water engineering were yellow card warning. Through the "co-management" of college-industry participation, professional has adjusted along with the market.

\section{Students' Academic Content Matches Professional Standards and Teaching Followed by the Market.}

The college has relied on the unique regional culture of Liaoshen area, and according to the fact that most students are employed in small and medium-sized enterprises, adheres to of principle of “deep cooperation, resource sharing, collaborative innovation, win-win”, aiming 
at serving local economic and social development, the regional economic and social development is a breakthrough point. It has conformed to such thinking as the talent cultivation goal needs the employment entrepreneurial of students, the talent cultivation process needs the talent cultivation goal, the graduates' quality needs the talent training objectives. According to the real production service technology and processes to build knowledge and technical skills systems, it has achieved "cooperation and making" in personnel training programs.

Throughout the teaching process, students have gradually guided to convert the theory into technology and convert technology into products. In terms of teaching content, business experts bring business practices into teaching practice in accordance with professional standards. According to the advice of business experts, the college timely has increased new knowledge, skills and techniques in the industry fields, and realized the content of students' learning content docking on social needs. In terms of teaching methods, based on action-oriented, to carry out "entrepreneurs into the classroom," "laboratory changing into the classroom," "factory workshop changing classroom," "the field to change the classroom", "art design studio changing classroom" etc.. College-enterprise dual-participation to ensure that students' abilities are fully improved. In terms of the evaluation of learning outcomes and assessment methods, adopting the ability-oriented evaluation concept, implementing a diversified assessment model, focusing on formative assessment, changing the college assessment for the college-enterprise co-assessment, change a single theory assessment for the "theory + practice" and "knowledge + skills" assessment, giving students' subjective initiative, school-enterprise "cooperation education" ,it has truly realized teaching followed by market.

\section{Renew Employment Concept, Innovate Cooperation Model, Realize New Upgrade of Students' Employment and Entrepreneurship}

In order to improve the quality of personnel training, colleges and enterprises jointly build secondary colleges, set up order classes, and provide internship positions to students, it take several forms to achieve "Co-building".

Based on the advantage in talent, technology, capital, equipment, setting up an $R \& D$ platform, accelerating the incubation of innovation and entrepreneurship, colleges and enterprises has promoted the transformation of technological achievements, especially the technological and product R\&D capabilities of small, medium and micro enterprises. College-enterprise, based on innovation entrepreneurship education, taking by innovation Entrepreneurial elite education, , integrating innovation and entrepreneurship education into the whole process of talent cultivation, it has realized "cooperation and research" in the field of scientific research.

\section{Constructing Diversified Teachers to Promote Team Transformation.}

Relying on the resource advantages, colleges and enterprises can jointly train teachers and engineering technicians, and provide comprehensive training and corporate practice opportunities for teachers, and provide basic training, technical training, and academic qualification training for engineers, both sides can improve their ability by means of "co-op training”.

In summary, through the above "6-co-op" model, namely "cooperation management, cooperation making, cooperation cultivating, cooperation building, cooperation training, cooperation research", it has implemented professional standards, curriculum systems, teaching standards and teaching materials , teaching aids, practical bases, student innovation 
and entrepreneurship centers, etc.. Throughout the entire process of personnel training, college-enterprise has realized coordination innovation, students have got familiar with the company's work process, mastered enterprise product technology, used the company's new technologies, quickly adopt to new corporate positions, provided new services for enterprise products, helped enterprises to increase the market share of products and solved the problem of technological innovation of service companies. Such students have already been in short supply.

\section{Docking the Market Demand, it has Got Outstanding Connotation Construction Achievements.}

\section{Professional Docking Industry, Significant Achievements in Professional Construction}

The college and enterprise have implemented "cooperation management", professional docking industry, and professional construction results are abundant.

The electronic information engineering subject was approved by the Ministry of Education in 2013 as a "comprehensive reform experimental subject". The plant production subject was approved by the Ministry of Education in 2014 as the first batch experimental subject "the outstanding agricultural and forestry talent education and training program". Such 2 subjects as mechanical design manufacturing and automation were awarded in 2017 "Transformation Development Demonstration Profession in Liaoning Province". Such 7 majors as computer science and technology were awarded the "Innovation and Entrepreneurship Reform experimental majors in Liaoning Province", "Advantages and features subjects in Liaoning Province", "Demonstration subjects in Liaoning Province", "Engineering Talents Training Model Reform experimental majors in Liaoning Province”.

\section{Academic Content Matches Professional Standards and Students are in Short Supply}

The teaching content docking on occupational standards, the student's learning content docking on the mainstream needs of enterprise, it has emerged the phenomenon of "pre-graduation and employment". The transportation subject has cooperated with Shenyang Passenger Transport Group, adjusted the original transportation subject to the direction of public traffic management, adjusted the content of 14 courses closely linked with the market. In 2017, 88 students in this subject were admitted to the Shenyang Metro Group. Of the 88 people, 35 people were 2018 students who had not yet graduated.

\section{Upgrade Cooperation Mode, Update Employment Concept and Provide a New Employment Channel for Students}

Through "co-building", cooperation has achieved remarkable results. Two alliances were awarded the "Alliance in Liaoning Province". Nine enterprise practice bases were approved as "Practical Education Bases in Liaoning Province" and four experimental centers were approved as "Experimental Teaching Demonstration Centers in Liaoning Province".

The college has adjusted cooperation mode. Students have begun to study i5 new technique, and students have followed the products to the enterprise which has bought the machine equipment. 


\section{"Co-research", Students' Achievements in Innovation and Entrepreneurship have Risen Steadily.}

Innovation teams for undergraduate students were established. Innovation and entrepreneurship training was actively carried out. An innovation and entrepreneurship incubation base was established. All teachers and students have solved technical problems for enterprises. The Innovation and Entrepreneurship Center has become "Demonstration Base in Liaoning Province" "the Public Business on Cloud in Liaoning Province" and "Star Innovation Space in Ministry of Education”.

College and enterprises have joined in the dual creation, inspired students to carry out the enthusiasm of innovation work, and got prominent success in Liaoning Province and national in the innovation and entrepreneurship competition. In the past five years, the students have published 895 papers, applied for 70 patents, established 249 innovative and entrepreneurial projects, received 1,528 innovation entrepreneurship competition awards, and received 183 awards for national-level innovation and entrepreneurship competitions.

\section{Summary}

Transformation and development is an important opportunity for the comprehensive and in-depth reform of newly-built undergraduate colleges. Shenyang Technology College has explored in the key tasks in running principle, running idea, internal operating mechanisms, deep co-op, and achieved initial experience. and However, there are still some problems in the work, such as the problem of the teaching staff construction, students' initiative in learning, etc..The College needs to continue to strengthen the confidence of transformation and development, and bear the unshirkable responsibility for improving the quality of application-oriented personnel training.

\section{Acknowledgment}

Fund Project: “Thirteenth Five Education Science Plan” Project of Liaoning Province (Project ID: JG17DB366) 2017 Educational Research Project of Liaoning Province Education Association (Project ID: LMJK2017008).

\section{References}

[1] Jingmin Cai, Guojiang Yu. From “” to “” Transition [J]. China Higher Education, 2016(6).

[2] Lin Yang. Transformation is beginning to fly [N]. China Education News, 2016-1-14(8).

[3] Piguo Gong. Market demand is the direction of running a college [N]. China Education News, 2017-9-20(11).

[4] Yongan Gu. Applying Undergraduate Professional Clusters: An Important Breakthrough in the Transformation and Development of Local Universities [J]. China Higher Education, 2016(11).

[5] Shuang Liang. The CDIO Engineering Education Reform by means of co-op [J]. China Electric Power Education, 2014(12). 
[6] Xiaohu Chen, Ying Nie. Running new application-oriented universities and develop new applied talents_ — Take the reform and development of Jinling Technology Institute as an example [J]. Journal of Jinling Technology Institute (Social Science Edition), 2017(12). 